\title{
Comparison of three distinct clean air suits to decrease the bacterial load in the operating room: an observational study
}

\author{
Piotr Kasina ${ }^{*}$, Ann Tammelin ${ }^{2}$, Anne-Marie Blomfeldt ${ }^{1}$, Bengt Ljungqvist ${ }^{3}$, Berit Reinmüller ${ }^{3}$ and Carin Ottosson ${ }^{1}$
}

\begin{abstract}
Background: Lowering air-borne bacteria counts in the operating room is essential in prevention of surgical site infections in orthopaedic joint replacement surgery. This is mainly achieved by decreasing bacteria counts through dilution, with appropriate ventilation and by limiting the bacteria carrying skin particles, predominantly shed by the personnel. The aim of this study was to investigate if a single use polypropylene clothing system or a reusable polyester clothing system could offer similar air quality in the operating room as a mobile laminar airflow device-assisted reusable cotton/polyester clothing system.

Methods: Prospective observational study design, comparing the performance of three Clean Air Suits by measuring Colony Forming Units (CFU) $/ \mathrm{m}^{3}$ of air during elective hip and knee arthroplasties, performed at a large university-affiliated hospital. The amount of $\mathrm{CFU} / \mathrm{m}^{3}$ of air was measured during 37 operations of which 13 were performed with staff dressed in scrub suits made of a reusable mixed material (69\% cotton, $30 \%$ polyester, $1 \%$ carbon fibre) accompanied by two mobile laminar airflow units. During 24 procedures no mobile laminar airflow units were used, 13 with staff using a reusable olefin fabric clothing (woven polypropylene) and 11 with staff dressed in single-use suits (non-woven spunbonded polypropylene). Air from the operating field was sampled through a filter, by a Sartorius MD8, and bacterial colonies were counted after incubation. There were 6-8 measurements from each procedure, in total 244 measurements. Statistical analysis was performed by Mann-Whitney U-test.
\end{abstract}

Results: The single-use polypropylene suit reduced the amount of $\mathrm{CFU} / \mathrm{m}^{3}$ to a significantly lower level than both other clothing systems.

Conclusion: Single-use polypropylene clothing systems can replace mobile laminar airflow unit-assisted reusable mixed material-clothing systems. Measurements in standardized laboratory settings can only serve as guidelines as environments in real operation settings present a much more difficult challenge.

Keywords: Orthopaedic surgery, Surgical clothing, Ventilation, Operating room, Air-borne bacteria

\section{Background}

Periprosthetic joint infection (PJI) is one of the most devastating complications after joint replacement surgery. In Sweden PJI is, together with loosening of the prosthesis, the most common reason for revision surgery after knee prosthesis surgery [1] and the second most common reason for revision after hip prosthesis surgery

\footnotetext{
* Correspondence: piotrkasina@yahoo.se

'Department of Clinical Science and Education, Orthopaedic Unit, Karolinska Institutet, Södersjukhuset, S-118 83 Stockholm, Sweden

Full list of author information is available at the end of the article
}

[2]. The consequences of these infections cause great physical and emotional suffering for the affected patients [3] and even increases mortality rate [4]. These complications create additional major costs for the health systems, in terms of vastly increased resource utilization through added and prolonged hospital stays and reoperations [5].

The necessity for limiting airborne bacteria in the operating room (OR), to establish a safer environment for orthopaedic implant surgery, has been well-established knowledge during the last decades [6, 7]. It is mainly 
achieved by a combination of adequate hygienic standards, good ventilation [8] and staff wearing clothing that reduces the emission of skin scales [9]. Requirements for clothing systems were set in 2009, as the European standard EN 13795 of the so-called Clean Air Suit [10].

Air quality can be assessed both by particle counting and microbiological sampling, but as the correlation between particle counts and microbial load is poor, it is preferable to measure Colony Forming Units (CFU) per cubic meter air [11].

In order to achieve as low CFU counts as possible, our department chose to complement our existing turbulent OR ventilation with additional mobile laminar airflow units (TOUL Meditech $\mathrm{AB}$, Västerås, Sweden). These can lower the CFU-counts over the operating field and instrument table by creating laminar airflow through sterile filters [12].

Unfortunately these devices were perceived to influence the working environment in a negative way. TOUL-devices are placed above the instrument table and on stands, very close to the operating table, thus intruding on the area for the operating team. The overall complexity of the OR also limits the placement of these devices, making it difficult to ensure and verify their correct positioning. Additionally they also create a disturbing background noise.

The aim of our study was therefore to investigate if we could achieve equal air quality with a different clothing system, without the use of TOUL-devices.

\section{Methods}

The study was conducted at the Dept. of Orthopaedics, Stockholm South General Hospital (Södersjukhuset AB), in 2013. The hospital holds 650 beds and employs 4400 co-workers, with Northern Europe's largest emergency department. The orthopaedic department performs over 6000 operations per year.

The surgical procedures included in the study (elective arthroplasties of hips and knees) were all performed in standardized setting, in the same OR, equipped with turbulent ventilation, HEPA-filter and air-intake of $620 \mathrm{~L} / \mathrm{s}$. Experienced orthopaedic surgeons with one junior assistant performed the elective arthroplasty procedures of both hips and knees (cemented, uncemented and hybrid solutions). In total there were between 6 and 9 staff present at each operation, including both the operating personnel, as well as the passive observers responsible for data collection. We had strict door control with only one opening throughout all of the operations.

Three clothing systems were studied prospectively, all supplied as brand-new. There were 13 operations performed in our currently used reusable mixed material
Mertex P-3477, Textilia AB (69 \% cotton, 30 \% polyester and $1 \%$ carbon fibre) accompanied by two TOUL devices (joint airflow $220 \mathrm{~L} / \mathrm{min}$ ). In 13 operations, garments from a reusable olefin fabric, Olefin, Textilia $A B$ (woven polypropylene/polyethene material) were used, without any TOUL device. The third clothing system, single-use BARRIER ${ }^{\circ}$ Clean Air Suit, Mölnlycke Health Care (non-woven, spunbonded polypropylene), was used to perform 11 procedures, also without any TOUL device. Both the Mertex P-3477 dress and the BARRIER ${ }^{\circ}$ Clean Air Suit, have cuffs at the bottom of the long legged pants and the short-sleeved shirts have cuffs at the arms, bottom and neckline. Olefin dresses had no cuffs at the bottom of the shirts and were therefore worn inside the pants.

The clothing systems were evenly distributed between morning and afternoon operations. During each operation, all staff present in the OR wore the same kind of clothes. These were later changed before next procedure.

Measurements were all performed by the same, experienced OR nurse, not involved in the surgical procedure. Air sampling was done with Sartorius Air Sampler MD8 $^{\circ}$ (Sartorius AG, Goettingen, Germany). Air was sucked with standardized airflow of $100 \mathrm{~L} / \mathrm{min}$ over a gelatine filter, placed $35-50 \mathrm{~cm}$ from the operating field, with special care regarding any splashes. It was changed every $10 \mathrm{~min}$, with six to eight measurements per operation. Each filter was placed, immediately after removal, on a sterile blood agar plate and sent to the laboratory of Clinical Microbiology at the Karolinska University Hospital in Huddinge the same day. The plates were then incubated for 2 days at $35^{\circ} \mathrm{C}$ and the amount of colonies were then counted and expressed as $\mathrm{CFU} / \mathrm{m}^{3}$.

Air sampling with condensate on the lid of the agar plate, macroscopic fluid or touch contamination, and damaged filters were excluded from analysis. Procedures with over $50 \%$ excluded samples were subsequently dropped from the analysis.

When analysing the data, we calculated the median and mean values of CFU for each operation as well as each clothing system. The Olefin clothing and the BARRIER $^{\circ}$ Clean Air Suit were then independently compared to our existing TOUL-assisted Mertex P-3477 garment. As outliers and non-standard distribution was observed in all three clean air suits, the comparison was based on median values, using the Mann-Whitney $U$-test.

\section{Results}

Our results are shown individually for each clothing system (Table 1, Table 2, and Table 3) and summarized for comparison (Table 4). The median values of the studied clothing systems were $20.0 \mathrm{CFU} / \mathrm{m}^{3}$ for the TOULassisted Mertex system, $22.5 \mathrm{CFU} / \mathrm{m}^{3}$ for the Olefin 
Table 1 Results from 13 operations performed with staff dressed in Mertex P-3477, Textilia AB with two TOUL devices

\begin{tabular}{lllclll}
\hline Operation & Nr of persons & Operation & \multicolumn{2}{c}{ CFU/m } & & Measurements/excluded (reason) \\
\cline { 3 - 5 } & in OR & & Median & Mean & Min - Max & \\
\hline 1 & 6 & Uncemented THR & 6.0 & 6.5 & $3-12$ & $6 / 0$ \\
3 & 6 & Cemented THR & 55.0 & 63.8 & $23-100$ & $7 / 1$ (fluid on filter) \\
4 & 6 & Cemented THR & 23.0 & 22.7 & $15-30$ & $7 / 1$ (fluid on filter) \\
5 & 6 & Cemented THR & 33.0 & 43.4 & $21-100$ & $7 / 2$ (1 condensate, 1 damaged filter) \\
6 & 6 & Cemented THR & 8.0 & 18.5 & $7-18$ & $7 / 3$ (condensate) \\
7 & 6 & Cemented THR & 15.0 & 22.2 & $8-55$ & $6 / 0$ \\
8 & 6 & Cemented THR & 8.0 & 10.8 & $6-20$ & $6 / 1$ (condensate) \\
9 & 6 & Hybrid THR & 46.0 & 61.3 & $23-148$ & $7 / 0$ \\
10 & 6 & Cemented THR & 42.0 & 40.9 & $17-58$ & $7 / 0$ \\
11 & 6 & Cemented THR & 24.0 & 24.9 & $12-40$ & $7 / 0$ \\
12 & 6 & Cemented THR & 16.0 & 16.3 & $6-24$ & $7 / 1$ (condensate) \\
13 & 6 & Uncemented THR & 8.5 & 10.2 & $6-17$ & $7 / 1$ (damaged filter) \\
\hline
\end{tabular}

OR Operating Room, CRU Colony Forming Units, THR Total Hip Replacement

system and $12 \mathrm{CFU} / \mathrm{m}^{3}$ for the BARRIER ${ }^{\circ}$ Clean Air Suit. We observed a wide spread of measurements between the different clothing systems, as well as between individual operations within the same clothing systems. The noticeably higher mean values $\left(27.9 \mathrm{CFU} / \mathrm{m}^{3}\right.$ of the TOUL-assisted Mertex system, $38.8 \mathrm{CFU} / \mathrm{m}^{3}$ of the Olefin clothing and $22.8 \mathrm{CFU} / \mathrm{m}^{3}$ of the BARRIER ${ }^{\circ}$ Clean Air Suit) reflect the impact of the outliers, present in every clothing system and shown under the max $\mathrm{CFU} / \mathrm{m}^{3}$ values in the tables. The reason of the high outlying values could not be traced back or explained by a specific date of surgery, temporary failure of ventilation or sterile processing department, malfunctioning Clean Air Suit items, nor the surgical teams or specific individuals.

Out of the total 244 measurements, we had to exclude 37 (15\%). This was done due to condensate on the lid of the agar plate (25 measurements), macroscopic fluid splash contaminations (7 measurements), damaged filter (4 measurements) and one tactile contamination. In three operations with the Olefin clothing, more than half of the measurements were excluded. Therefore, these three procedures were not regarded as representable and were consequently eliminated from the

Table 2 Results from 13 operations performed with staff dressed in Olefin, Textilia AB

\begin{tabular}{|c|c|c|c|c|c|c|}
\hline \multirow[t]{2}{*}{ Operation } & \multirow{2}{*}{$\begin{array}{l}\mathrm{Nr} \text { of persons } \\
\text { in OR }\end{array}$} & \multirow[t]{2}{*}{ Operation } & \multicolumn{3}{|l|}{$\mathrm{CFU} / \mathrm{m}^{3}$} & \multirow[t]{2}{*}{ Measurements/excluded (reason) } \\
\hline & & & Median & Mean & Min - Max & \\
\hline 1 & 6 & Uncemented THR & 36.5 & 37.0 & $20-57$ & $6 / 0$ \\
\hline 2 & 6 & Cemented THR & 2.5 & 2.7 & $0-6$ & $6 / 0$ \\
\hline 3 & 6 & Cemented THR & 112.0 & 177.0 & 44-188 & $6 / 0$ \\
\hline 4 & 6 & Cemented THR & 66.0 & 106.0 & $50-228$ & $6 / 0$ \\
\hline 5 & 6 & Cemented THR & 17.5 & 20.7 & $1-40$ & $6 / 0$ \\
\hline 6 & 6 & Cemented THR & 5.0 & 7.3 & $1-18$ & 7/1 (fluid on filter) \\
\hline 7 & 8 & Cemented THR & 37.5 & 35.2 & $22-48$ & $6 / 0$ \\
\hline 8 & 8 & Hybrid THR & 22.5 & 24.5 & $14-40$ & $6 / 0$ \\
\hline 9 & 8 & Cemented THR & 7.0 & 8.0 & $2-16$ & $8 / 2$ ( 1 damaged filter, 1 tactile contamination) \\
\hline 10 & 9 & Cemented THR & a & a & ${ }^{a}(2-6)$ & 7/4 (condensate) \\
\hline 11 & 8 & Cemented THR & a & a & ${ }^{\mathrm{a}}(2)$ & 7/6 (condensate) \\
\hline 12 & 6 & Uncemented THR & a & a & $\mathrm{a}(4-6)$ & 7/5 (condensate) \\
\hline 13 & 6 & Cemented THR & 22.5 & 25.0 & $10-45$ & 7/3 (condensate) \\
\hline
\end{tabular}


Table 3 Results from 13 operations performed with staff dressed in BARRIER ${ }^{\circledR}$ Clean Air Suit, Mölnlycke Health Care

\begin{tabular}{|c|c|c|c|c|c|c|}
\hline \multirow[t]{2}{*}{ Operation } & \multirow{2}{*}{$\begin{array}{l}\text { Nr of persons } \\
\text { in OR }\end{array}$} & \multirow[t]{2}{*}{ Operation } & \multicolumn{3}{|l|}{$\mathrm{CFU} / \mathrm{m}^{3}$} & \multirow{2}{*}{$\begin{array}{l}\text { Measurements/excluded } \\
\text { (reason) }\end{array}$} \\
\hline & & & Median & Mean & Min - Max & \\
\hline 1 & 9 & Uncemented THR & 7.0 & 7.3 & $3-14$ & $6 / 0$ \\
\hline 2 & 8 & Cemented THR & 3.0 & 3.0 & $0-8$ & 7/1 (fluid on filter) \\
\hline 3 & 8 & Cemented THR & 6.0 & 7.8 & $3-18$ & $7 / 2$ (1 fluid on filter, 1 condensate) \\
\hline 4 & 8 & Cemented THR & 6.5 & 7.8 & $2-16$ & $6 / 0$ \\
\hline $5^{\mathrm{a}}$ & 8 & Cemented THR & 5.0 & 6.7 & $3-13$ & 7/1 (fluid on filter) \\
\hline 6 & 8 & Cemented TKR & 26.0 & 29.3 & $17-45$ & 7/1 (fluid on filter) \\
\hline 7 & 8 & Cemented TKR & 28.5 & 30.0 & $11-50$ & $6 / 0$ \\
\hline 8 & 8 & Hybrid THR & 22.5 & 20.0 & $5-35$ & $6 / 0$ \\
\hline 9 & 8 & Cemented THR & 23.5 & 80.5 & $1-280$ & $6 / 0$ \\
\hline 10 & 7 & Cemented THR & 47.5 & 46.3 & $25-71$ & 7/1 (damaged filter) \\
\hline 11 & 8 & Cemented THR & 10.0 & 10.0 & 13-19 & $6 / 0$ \\
\hline
\end{tabular}

OR Operating Room, CRU Colony Forming Units, THR Total Hip Replacement, TKR Total Knee Replacement

${ }^{\mathrm{a}} 1$ door opening

analysis. Conclusively we analyzed 201 measurement, 78 of which with the TOUL-assisted Mertex system, 58 with the Olefin clothing and 65 measurements with the BARRIER ${ }^{\odot}$ Clean Air Suit.

The only door opening, on the fifth operation with BARRIER $^{\oplus}$ Clean Air Suit, did not show any evident rise in measured CFU-values.

Our main finding was the lowest median $\mathrm{CFU} / \mathrm{m}^{3}$ of the BARRIER ${ }^{\circledR}$ Clean Air Suit, which was significantly lower ( $p$ 0.009) and therefore superior to our standard clothing, the TOUL-assisted Mertex. The Olefin suit had the highest median and mean values of all three tested systems and did not show any significant difference to the TOUL-assisted Mertex system.

\section{Discussion}

The most common OR environment in Sweden, for joint replacement surgery, is turbulent, mixed airflow combined with usage of reusable mixed (cotton/polyester) clothing. Previous studies have shown that polyester clothing is superior to both cotton and reusable mixed clothing (cotton/polyester). As a result of previous measurements [13] and evaluation of our working environment, our department used mixed garments with

Table 4 Comparison of all tree clothing systems

\begin{tabular}{|c|c|c|c|c|}
\hline \multirow[t]{2}{*}{ Clothing system } & \multicolumn{3}{|l|}{$\mathrm{CFU} / \mathrm{m}^{3}$} & \multirow[t]{2}{*}{$\overline{p \text {-value }}$} \\
\hline & Median & Mean & Min - Max & \\
\hline $\begin{array}{l}\text { Mertex P-3477 + two } \\
\text { TOUL devices }\end{array}$ & 20.0 & 27.9 & $1-148$ & - \\
\hline Olefin clothing & 22.5 & 38.8 & $0-228$ & 0.622 \\
\hline BARRIER $^{\oplus}$ Clean Air Suit & 12.0 & 22.8 & $0-280$ & 0.009 \\
\hline
\end{tabular}

CFU Colony Forming Units

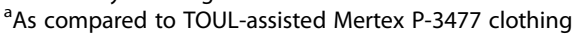

additional TOUL-devices, shown to further improve air quality [12].

Single-use polypropylene clothing has also been shown to be superior to reusable mixed clothing [14]. Our study shows that the single-use polypropylene clothing is able to reduce the bacterial counts more than both TOUL-assisted reusable mixed material clothing and reusable olefin clothing.

Door openings and increased traffic flow have a negative impact on bacterial contamination in the air [15]. In spite of our strict control, one opening was necessary during the 37 studied operations. Although it did not translate into any raise of CFU counts, this would be the expected outcome in repetitive cases.

Improving the ventilation system by rebuilding or new installation is appealing. However it is not possible in the short term or without erection of new facilities. Moreover decreasing the CFU counts by dilution through increased airflow with existing ventilation system is not easy. Heat generated by medical equipment and personnel, together with their diverse activities, different quantities or numbers, at times diverse placements and not infrequent (at multidisciplinary centers) special constellations, creates inevitably highly variable environments. Computed air velocity models have shown powerful vortex patterns even in assumed predictable, standardized settings. Reversed flows can build up inlet jets, between the patient and medical personnel, carrying air from floor level into the critical, operating field [16]. These streams can be both strong and unpredictable. Simultaneously the reach of mobile laminar airflow units is limited and sensitive to positioning, especially in a busy OR with limited space around the patient. 
It is important for our patients that operating personnel can perform in an anticipated environment in the OR. It is thus necessary for all staff to use a well-known and commonly agreed clean air suit.

Manufacturers have to test their clothing systems in closed chambers and standardized settings for certification purposes. Ventilation systems are also assessed, before their usage in real life is commenced. Our ethical commitment to best patient care, does not allow testing these factors, as well as many other features, in real treatment prior to certification. The BARRIER ${ }^{\circ}$ Clean Air Suit was our most stable performer, although its results varied noticeably. The variation, as the previously mentioned outliers of all three garments, could not be explained by variations in number of staff in the OR, the individuals within each operating team, the specific procedure performed, door openings or the ventilation. This difficulty reflects the complex and multifactorial relationship of real conditions of the ORs environment. Industrial standards therefore fail to predict the real outcome [14].

According to recommendations for air in operating rooms for infection-prone clean surgery the CFU-counts should be $\leq 5 \mathrm{CFU} / \mathrm{m} 3$ when clean air suits are worn [17]. The present study shows that this is not possible to achieve in our ORs with the present ventilation but also shows the importance of comparing available clothing systems to make the best choice. It is out of the scope of this study to make a cost benefit analysis on infection rates for the three clothing systems studied. With current prices the cost for the orthopaedic department, however, is the same regardless of which one of the clothing system is chosen.

Our department now continues clinical work with the BARRIER $^{\oplus}$ Clean Air Suit. A new operating department, with better ventilation, is currently under construction and is expected to be ready and fully operational in 3 years. Concurrently we are looking at the market for additional devices to be placed inside the existing ORs, to further increase the turbulent ventilation.

\section{Conclusions}

A single use polypropylene clothing system can offer better CFU reduction then both reusable olefin and mobile laminar airflow unit-assisted cotton/polyester clothing systems. Measurements in standardized settings can only serve as guidelines, as values in real operation settings can differ and be difficult to reproduce. Better theoretical and real evaluation models are required for satisfactory measurements and quality control for our patients.

\section{Competing interests}

\section{Financial support}

The study was supported by the Dept. of Orthopaedics, Stockholm South General Hospital, Sweden. Anne-Marie Blomfeldt received salary support from Mölnlycke Health Care. All three clothing systems were supplied by the manufacturers (Mölnlycke Health Care, Sweden and Textilia AB, Sweden), free of charge.

\section{Potential conflicts of interest}

No author report any conflicts of interest relevant to this article other than what is mentioned under financial support.

\section{Authors' contributions}

PK participated in the design and coordination of the study and interpretation of data, performed the statistical analysis and drafted the manuscript. AT participated in the design, coordination and supervision of the study, helped with the statistical analysis and interpretation of data and to draft the manuscript. A-MB participated in the coordination of the study, was responsible for sampling during operations, collection of data and helped to draft the manuscript. BL participated in the design and coordination of the study, helped with sampling and interpretation of data and to draft the manuscript. BR participated in the design and coordination of the study, helped with sampling and interpretation of data and to draft the manuscript. CO was involved in the design, coordination and supervision of the study, assisted with the statistical analysis and interpretation of data and helped to draft the manuscript. All authors read and approved the final manuscript.

\section{Acknowledgements}

To the staff from the laboratory at the Department of Clinical Microbiology, Karolinska University Hospital in Huddinge, for their technical assistance.

\section{Author details}

${ }^{1}$ Department of Clinical Science and Education, Orthopaedic Unit, Karolinska Institutet, Södersjukhuset, S-118 83 Stockholm, Sweden. ${ }^{2}$ Department of Medicine, Solna (MedS), Unit of Infectious Diseases, Karolinska Institutet, Stockholm, Sweden. ${ }^{3}$ Department of Energy and Environment, Division of Building Services Engineering, Chalmers University of Technology, Göteborg, Sweden.

Received: 15 October 2015 Accepted: 28 December 2015

Published online: 07 January 2016

\section{References}

1. Sundberg M, Lindgren L, W-Dahl A, Robertsson O. Swedish knee arthroplasty register -annual report. 2014. http://myknee.se/pdf/SKAR2014_ Eng_1.1.pdf.

2. Garellick G, Kärrholm J, Lindahl H, Malchau H, Rogmark C, Rolfson O. Swedish Hip arthroplasty register -annual report. 2013. http://www.shpr.se/ Libraries/Documents/AnnualReport_2013-04-1_1.sflb.ashx.

3. Andersson AE, Bergh I, Karlsson J, Nilsson K. Patients' experiences of acquiring a deep surgical site infection: An interview study. Am J Infect Control. 2010;38:711-7.

4. Zmistowski B, Karam JA, Durinka JB, Casper DS, Parvizi J. Periprosthetic joint infection increases the risk of One-year mortality. J Bone Joint Surg Am. 2013;95A:2177-84

5. Bozic KJ, Ries MD. The impact of infection after total hip arthroplasty on hospital and surgeon resource utilization. J Bone Joint Surg-Am. 2005:87A:1746-51.

6. Charnley J, Eftekhar N. Postoperative infection in total prosthetic replacement arthroplasty of the hip-joint. With special reference to the bacterial content of the air of the operating room. Br J Surg. 1969:56:641-9.

7. Lidwell OM, Lowbury EJL, Whyte W, Blowers R, Stanley SJ, Lowe D. Airborne contamination of wounds in joint replacement operations - the relationship to sepsis rates. J Hosp Infect. 1983;4:111-31.

8. Lahmer A, Lehnhardt M, Steinau HU, Hirsch T, Hubert $H$, Fischer S, et al. Bacterial burden in the operating room: impact of airflow systems. Am J Infect Control. 2012;40:E228-32.

9. Tammelin A, Hambraeus A, Stahle E. Routes and sources of staphylococcus aureus transmitted to the surgical wound during cardiothoracic surgery: possibility of preventing wound contamination by use of special scrub suits. Infect Control Hosp Epidemiol. 2001;22:338-46.

10. European Committee for Standardization, European Standard EN 13795, ICS 11.140 2011. http://www.sis.se/hälso-och-sjukvård/sjukvårdstextilier-allmänt/ ss-en-137952011.

11. Panatto D, Gasparini R, Orlando P, Cristina ML, Spagnolo AM, Sartini M, et al. Can particulate Air sampling predict microbial load in operating theatres for arthroplasty? PLoS One. 2012;7:e52809. 
12. Saccani E, Fanti M, Moscato U, Giannetti G, Pasquarella C, Sansebastiano GE, et al. A mobile laminar airflow unit to reduce air bacterial contamination at surgical area in a conventionally ventilated operating theatre. J Hosp Infect. 2007:66:313-9.

13. Tammelin A, Ljungqvist B, Reinmuller B. Comparison of three distinct surgical clothing systems for protection from air-borne bacteria: a prospective observational study. Patient saf surg. 2012;6:23.

14. Tammelin A, Ljungqvist B, Reinmuller B. Single-use surgical clothing system for reduction of airborne bacteria in the operating room. J Hosp Infect. 2013;84:245-7.

15. Andersson AE, Bergh I, Karlsson J, Eriksson Bl, Nilsson K. Traffic flow in the operating room: an explorative and descriptive study on air quality during orthopedic trauma implant surgery. Am J Infect Control. 2012;40:750-5.

16. Sadrizadeh S, Tammelin A, Ekolind P, Holmberg S. Influence of staff number and internal constellation on surgical site infection in an operating room. Particuology. 2014;13:42-51.

17. Microbiological cleanliness in the operating room - Preventing airborne contamination - Guidance and fundamental requirements. SIS-TS 39:2012, english version. Swedish Standards Institute, Stockholm 2013

\section{Submit your next manuscript to BioMed Central} and we will help you at every step:

- We accept pre-submission inquiries

- Our selector tool helps you to find the most relevant journal

- We provide round the clock customer support

- Convenient online submission

- Thorough peer review

- Inclusion in PubMed and all major indexing services

- Maximum visibility for your research

Submit your manuscript at www.biomedcentral.com/submit 